\title{
Heat Treatment Effects on ASTM A890/A 890M GR 5A Super Duplex Stainless Steel Passivity
}

\author{
Hillane Mirelle Lopes Ferreira de Lima ${ }^{a}$, Ivan Napoleão Bastos ${ }^{b}$, Walney Silva Araújo ${ }^{\text {, }}$
}

\author{
Marcelo Martins ${ }^{c}$
}

\author{
${ }^{a}$ Departamento de Engenharia Metalúrgica e Materiais, Universidade Federal do Ceará (UFC), Av. \\ Mister Hull, s/n, Pici, Fortaleza, CE, Brazil \\ ${ }^{b}$ Departamento de Materiais, Universidade do Estado de Rio de Janeiro, Instituto Politécnico, Rua \\ Bonfim, 25, Vila Amélia, Nova Friburgo, RJ, Brazil \\ ${ }^{c}$ Sulzer Brasil S/A, Rua Eng João Fernandes Gimenez Molina, 905, Jundiaí, SP, Brazil
}

Received: September 26, 2017; Revised: December 07, 2017; Accepted: December 08, 2017

\begin{abstract}
Heat treatment can modify the corrosion resistance of stainless steels. Thus, the corrosion behavior of ASTM A890/A 890M GR 5A super duplex stainless steels (SDSS) has been investigated in aqueous $60,000 \mathrm{ppm} \mathrm{NaCl}$ solution by several electrochemical tests. The specimens were aged for 2, 10, 50 and 100 hours at $475^{\circ} \mathrm{C}$. Potentiodynamic polarization studies showed that, when the corrosion potential comes to the passivation state, a peak current is detected at about $400 \mathrm{mV}$ vs. $\mathrm{Ag} / \mathrm{AgCl}$, with a strong influence on the film stability. The peak current value increased with the aging time; the highest peak value was for the sample aged for $100 \mathrm{~h}$. Three potentials were chosen from the polarization curves in order to evaluate the sample/film/solution behavior and their changes over the passivation range. The results indicate that the passive film was degraded with the increase of the aging time. In addition, the results of the corrosion tests were compared with the evolution of the mechanical properties of the steels by the Vickers microhardness test.
\end{abstract}

Keywords: Super duplex stainless steels, passivity, aging, heat treatment.

\section{Introduction}

Super duplex stainless steels (SDSS) with approximately equal volume fractions (about $50 \%$ ) of ferrite $(\alpha)$ and austenite $(\gamma)$ have been widely used in the oil, chemical, petrochemical, and nuclear industries due to their high mechanical strength, good weldability, and excellent resistance to localized and stress corrosion ${ }^{1-4}$. These alloys are defined as the steels for which the empirical pitting resistance equivalent numbers (PREN) equation is greater than $40^{2,4,5}$.

Once the chemical composition is established, the properties of SDSS are strongly dependent on their thermal history, which greatly influences the microstructure and composition of each phase. These types of steels are intrinsically subject to embrittlement when exposed in the temperature range of $280-500^{\circ} \mathrm{C}$ because of solid-state reactions within the ferrite phase ${ }^{6}$. This phenomenon is termed $475^{\circ} \mathrm{C}$ embrittlement as its rate is highest at $475^{\circ} \mathrm{C}$. The spinodal decomposition of the ferritic phase to chromium-rich phase, $\alpha^{\prime}$, and iron-rich phase, $\alpha$, in the temperature range of $280-500{ }^{\circ} \mathrm{C}$ due to the presence of the miscibility gap in iron-chromium binary alloy system ${ }^{6}$ causes SDSS to be embrittled by lowering the mobility of dislocation and by creating microvoids near the ferrite matrix, then forming the $\mathrm{Cr}$-depleted regions around them and further, which can degrade the passive film of these alloys ${ }^{7-9}$. Other precipitation processes would

*e-mail: hillanemirelle@gmail.com also occur, the main one being the precipitation of $\mathrm{Ni}, \mathrm{Si}$, Mo-rich G-phase ${ }^{7,8,10,11}$. The G-phase appears at $475^{\circ} \mathrm{C}$, with an incubation time, after the spinodal decomposition and requires a very long aging time to reach uniformity in the ferritic matrix ${ }^{6,12}$. The presence of G-phase in the ferrite contributes to increase the hardness of ferrite, but from the literature reports, the spinodal decomposition features an effect of hardening that is more pronounced than the one caused by the formation of the G-phase ${ }^{13}$.

The literature shows that the corrosion resistance of stainless steels is primarily attributed to the passive film growth on its surface ${ }^{14-16}$. The changes in the passive film and the breakdown of the passive film directly affect the localized corrosion resistance leading to pitting corrosion, crevice corrosion, intergranular corrosion and stress corrosion cracking. Therefore, understanding the passivity properties is a key factor for the protection of stainless steels against localized corrosion attack, and one of the most common approaches to reduce localized corrosion-related failures involves the selection of resistant material by suitable alloying.

Given the difficulty of analyzing $\alpha$ ' precipitates by optical or electron microscopy, some researchers have tried to assess the degree of $475^{\circ} \mathrm{C}$ embrittlement of the alloys in terms of the change in electrochemical and mechanical properties induced by the precipitation of $\alpha^{\prime}$ phase $e^{6,7,17,18}$. Although the effect of $\alpha^{\prime}$ precipitation is known, it is important to characterize the 
degree of embrittlement of the material with different aging times, by means of a study of its passivity.

The aim of this work is the evaluation of the heat treatment effects on a cast SDSS passivation using electrochemical techniques. The heat treatments consisted of heating at 475 ${ }^{\circ} \mathrm{C}$ for four different times, 2, 10, 50 and $100 \mathrm{~h}$. Vickers microhardness (HV) measurements were also carried out for each condition to study the influence of $\alpha$ ' phase precipitate on the phase hardness, and the microstructure changes were related to the corrosion results.

\section{Experimental}

The SDSS used in this work was a cast stainless steel (ASTM A890/A 890M GR 5A) that was provided by Sulzer Brazil S/A. The chemical composition and the PRE index for this alloy are presented in Table 1 . The as-received samples were annealed at $1120^{\circ} \mathrm{C}$ for $4 \mathrm{~h}$ and water-quenched, and then aged respectively, for $2,10,50$ and $100 \mathrm{~h}$ at $475^{\circ} \mathrm{C}$. The heat treatment was performed in a muffle furnace. The objective of the solution annealing heat treatment before aging was to obtain complete dissolution of the precipitates in the ferrite matrix and at the $\alpha / \gamma$ interfaces ${ }^{19}$. Before electrochemical tests, the specimens were abraded with silicon carbide paper up to 600 mesh, degreased with alcohol, washed with distilled water and dried with hot air. Some specimens were polished to a $1 \mu \mathrm{m}$ finish before testing for metallographic observations. Microstructures were revealed by Beraha reagent $\left(20 \mathrm{~mL} \mathrm{HCl}, 80 \mathrm{~mL} \mathrm{H}_{2} \mathrm{O}\right.$, and $1 \mathrm{~g}$ of potassium metabisulfide), which made the austenite phase light and the ferrite phase dark, and observed with an optical microscopy.

The effects of the aging on the passivity of the SDSS were evaluated by an anodic polarization test, chronoamperometry, electrochemical impedance spectroscopy (EIS) and a galvanic corrosion test. The electrochemical tests were conducted in a naturally aerated solution of $60,000 \mathrm{ppm}$ $\mathrm{NaCl}$ at $25.0 \pm 0.2{ }^{\circ} \mathrm{C}$. The anodic polarization test and electrochemical impedance spectroscopy were conducted in a potentiostat-galvanostat Autolab model PGSTAT302N. The chronoamperometry and galvanic corrosion test were performed in a potentiostat/galvanostat/ZRA Gamry Instruments System (Reference 600, Gamry Instruments), controlled by the Gamry Instruments Framework software. A conventional three-electrode electrochemical cell using a platinum $(\mathrm{Pt})$ grid as the counter electrode, saturated $\mathrm{KCl}$ silver/silver chloride $(\mathrm{Ag} / \mathrm{AgCl})$ as the reference electrode and the working electrode was constructed using the steel samples embedded in epoxy resin. The working electrode area exposed to the test solution was approximately 0.5 $\mathrm{cm}^{2}$. Polarization and chronoamperometry tests were started after a nearly steady-state open circuit potential (OCP) had developed (around one hour). Anodic polarization tests were performed at a scan rate of $1.0 \mathrm{mVs}^{-1}$ until the current density of $1.0 \mathrm{~mA}$ was reached. The surface of the specimen subject to an anodic polarization was observed just after the test by optical microscopy. Three values of potential were selected in the polarization curves in order to investigate the peak on the passivation range: open circuit potential (OCP), E2 $=400$ $\mathrm{mV}, \mathrm{E} 3=850 \mathrm{mV}$ vs. $\mathrm{Ag} / \mathrm{AgCl}$. The analysis was carried out by EIS experiments at a frequency range from $10 \mathrm{kHz}$ to $2.5 \mathrm{mHz}$ and with a perturbation amplitude of $20 \mathrm{mV}$ at an acquisition rate of 7 points per decade. In order to guarantee the stationary and linear conditions, the working electrode was polarized for $1 \mathrm{~h}$ according to the measured potential before measuring the impedance tests. Chronoamperometry was used to evaluate the evolution of the current density flowing into the cell as a function of the time by application of constant potential for $4 \mathrm{~h}$. The applied potential was 400 $\mathrm{mV}$ (vs. $\mathrm{Ag} / \mathrm{AgCl}$ ), which is the observed anodic peak. In the experimental schema of the galvanic corrosion test, the working electrodes were the aged and the annealed (at 1120 $\left.{ }^{\circ} \mathrm{C}\right)$ samples. The time recording of the common potential and the current between the aged samples and the annealed sample over time is an indication of galvanic effects. The surfaces of these two specimens were also placed parallel and separated by $5.0 \mathrm{~mm}$ in the electrolyte. The frequency of sampling was $1.0 \mathrm{~Hz}$ and the recording time was $24 \mathrm{~h}$. All electrochemical measurements were repeated at least three times for each condition to obtain representative results.

The Vickers microhardness of ferrite and austenite phases was measured for the detection of embrittlement owing to thermal aging. To determine the microhardness values of the phases and correlate them with the aging treatment time, Vickers microhardness measurements were performed with a load of $100 \mathrm{gf}$ and the holding time for the measurements was $15 \mathrm{~s}$. The mean and standard deviation values were obtained based on ten prints in each phase.

\section{Results and Discussion}

The PREN value, calculated from Eq. (1), by chemical compositions (wt.\%) of the stainless steel studied in this work indicates that it is classified as super duplex stainless steel (see Table 1). Figure 1 shows optical micrographs of the microstructure of specimens annealed (at $1120{ }^{\circ} \mathrm{C}$ for $4.0 \mathrm{~h}$ ) and aged (at $475^{\circ} \mathrm{C}$ for 2, 10, 50 and $100 \mathrm{~h}$ ). The typical ferrite-austenite duplex structure was observed. The austenite phase (bright phase) was evenly distributed as islands in the etched ferrite matrix (dark phase). The nominal

Table 1. Chemical composition for the super duplex stainless steel (\% wt.).

\begin{tabular}{ccccccccccc}
\hline & $\mathrm{C}$ & $\mathrm{Cr}$ & $\mathrm{Ni}$ & $\mathrm{Mn}$ & $\mathrm{Si}$ & $\mathrm{Mo}$ & $\mathrm{Cu}$ & $\mathrm{N}$ & $\mathrm{Fe}$ & PREN \\
\hline $\mathbf{5 A}$ & 0.028 & 25.51 & 7.84 & 0.96 & 0.70 & 4.25 & 0.30 & 0.249 & Bal. & 43.5 \\
\hline
\end{tabular}




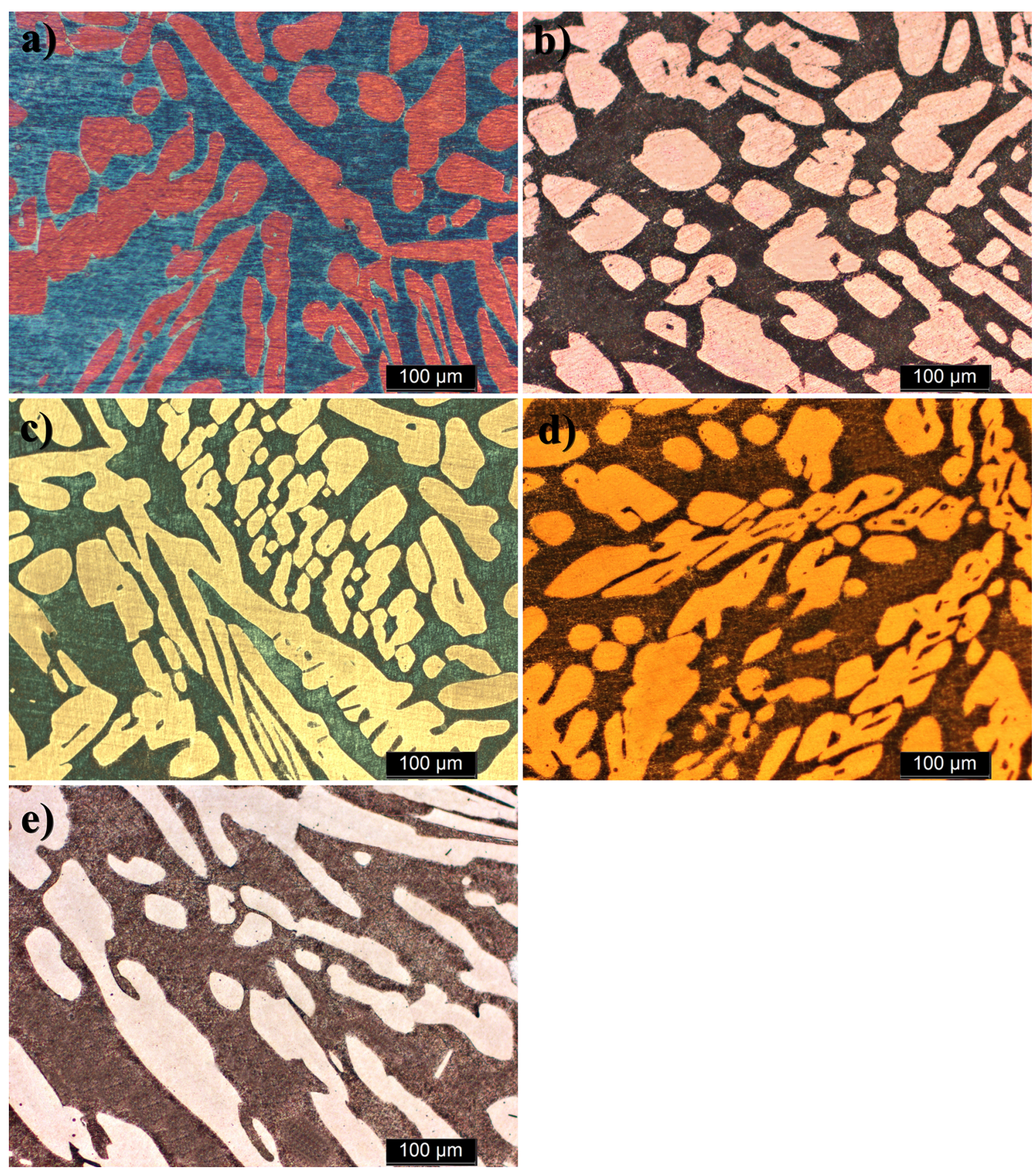

Figure 1. Optical micrographs of the microstructures of samples: (a) annealed and aged at $475^{\circ} \mathrm{C}$ for (b) $2 \mathrm{~h}$, (c) $10 \mathrm{~h}$, (d) $50 \mathrm{~h}$, (e) $100 \mathrm{~h}$.

volume fractions of both ferrite $(\alpha)$ and austenite $(\gamma)$ in all the samples, measured by quantitative optical microscopy, remained unchanged with aging time and were close to $50 \%$. Optical micrographs (OM) analysis did not reveal significant microstructural changes in the samples because the $\alpha^{\prime}$ phase is very thin (in the order of nm), making it undetectable in this kind of analysis. These results are in good agreement with the literature, which reports that microstructural changes in SDSS at low temperatures occur at the nanometric scale and are not visible by $\mathrm{OM}$ and/or scanning electron microscopy
(SEM), requiring the use of higher resolution techniques such as TEM to observe them ${ }^{7,8,20,21}$.

$$
\text { PREN }=w t . \% C r+3.3 w t . \% M o+16 w t . \% N
$$

Figure 2 and Table 2 show the variation of Vickers microhardness values in ferrite and austenite phases as a function of thermal aging time. Hardness measurements were taken using two nominally identical specimens. The indicative values of hardness represent the arithmetic average of 20 
Table 2. Vickers microhardness of $\alpha$ and $\gamma$ phases.

\begin{tabular}{cccc}
\hline Heat treat. Temp. $\left({ }^{\circ} \mathrm{C}\right) /$ Time $(\mathrm{h})$ & Phases & Average (HV 100 gf) & Standard Deviation \\
\hline \multirow{2}{*}{ Annealed } & $\gamma$ & 283.3 & 6.43 \\
\multirow{2}{*}{$\mathbf{4 7 5}^{\circ} \mathbf{C} / \mathbf{2 ~ h}$} & $\alpha$ & 333.0 & 8.44 \\
& $\gamma$ & 293.2 & 6.43 \\
$\mathbf{4 7 5}^{\circ} \mathbf{C} / \mathbf{~} \mathbf{0 ~ h}$ & $\alpha$ & 482.4 & 7.43 \\
& $\gamma$ & 372.0 & 7.36 \\
$\mathbf{4 7 5}^{\circ} \mathbf{C} / \mathbf{5 0 ~ h}$ & $\alpha$ & 626.0 & 20.29 \\
& $\gamma$ & 314.7 & 22.54 \\
$\mathbf{4 7 5}^{\circ} \mathbf{C} / \mathbf{~} \mathbf{1 0 0 ~ h}$ & $\alpha$ & 551.2 & 21.33 \\
\hline
\end{tabular}

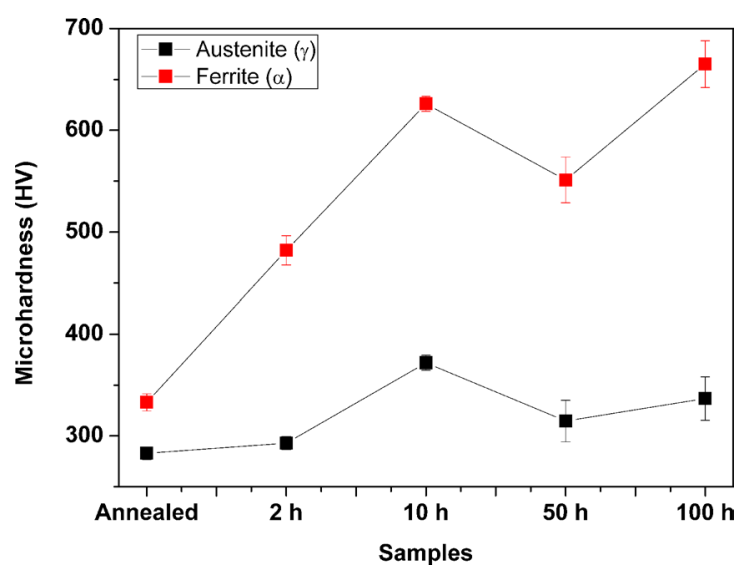

Figure 2. Microhardness of samples annealed and aged at $475^{\circ} \mathrm{C}$ for: $2,10,50$ and $100 \mathrm{~h}$.

measurements. During aging, as this figure shows, the hardness of the ferrite phase increases significantly. The accentuated increase in ferrite hardening for samples aged at $475{ }^{\circ} \mathrm{C}$ is related to the obstruction of the movement of dislocations caused by the precipitation of nanometric scale $\alpha$ ' phase. In contrast, the hardness of austenite phase remains essentially unchanged, indicating that the austenite is unaffected by the aging treatment. Note that ferrite microhardness undergoes a marked increase of approximately $40 \%$ in the initial hours of aging, and then reaches the highest value for the sample aged at $475^{\circ} \mathrm{C}$ for $100 \mathrm{~h}$. The reason for this observation is probably that increasing the thermal aging time leads to the formation of increasing numbers of $\alpha^{\prime}$ precipitates in the ferrite phase. This result also suggests that the embrittlement phenomenon of the present super duplex stainless steel is presumably connected with the microstructural evolution of ferrite phase, a fact that is in good agreement with other studies $^{13,19,22}$, which also found that microstructural changes by aging at $475^{\circ} \mathrm{C}$ occurred mainly in the ferrite phase.

The microhardness of ferrite phase was selected as the mechanical property to represent the degree of embrittlement of SDSS, in other words the precipitation of Cr-rich $\alpha^{\prime}$ precipitates, as it was found to be the most sensitive parameter that characterizes the embrittlement of the material.
The evolution of open circuit potentials (OCP) for each heat treatment condition monitored versus time in 60,000 ppm $\mathrm{NaCl}$ solution is shown in Figure 3. A higher OCP usually indicates an increase in the passivation ability of the steel. As a general tendency, the potential increased as soon as the samples were immersed in the electrolyte and then stabilized after about $1800 \mathrm{~s}$.

The measurement of the steady-state anodic polarization curve over the wide potential range is usually a first step in studying passivity. Figure 4 shows the anodic potentiodynamic polarization curves of super duplex stainless steel under the different heat treatment conditions in $60,000 \mathrm{ppm} \mathrm{NaCl}$ solution. The typical anodic polarization behavior of a stainless steel in $\mathrm{NaCl}$ solution consists of active dissolution (around the anodic peak), passivity, and a rapid increase of the current density. It is worth noting that no significant changes occur in the corrosion potential $\left(\mathrm{E}_{\text {corr }}\right)$. Samples annealed and aged at 475 ${ }^{\circ} \mathrm{C}$ for 2 and 10 hours presented a low current density, around a few $\mu \mathrm{Acm}^{-2}$ up to $1.0 \mathrm{~V}$ (vs. $\mathrm{Ag} / \mathrm{AgCl}$ ). The abrupt increase of current, for these samples, was felt in the potential range where oxygen evolution could already thermodynamically take place. At higher potentials, the oxygen anodic reaction seemed to participate in pitting nucleation through the formation of a triple interface between the metal, electrolyte, and oxygen bubbles ${ }^{23}$. Indeed, a previous measurement performed on a Pt electrode in this test solution had indicated that the evolution of $\mathrm{O}_{2}$ was about $1.05 \mathrm{~V}$ vs. $\mathrm{Ag} / \mathrm{AgCl}$ at $25.0^{\circ} \mathrm{C}$. Therefore, the steep increase at $\sim 1.0 \mathrm{~V}$ vs. $\mathrm{Ag} / \mathrm{AgCl}$ for these samples is likely due not to pitting corrosion but to the onset of oxygen evolution. For sample aged at $475^{\circ} \mathrm{C}$ for 50 hours, the curve seems to be an attempt to active-passive transition in $\mathrm{E} 2$ potential (400 mV vs. $\mathrm{Ag} / \mathrm{AgCl})$, with current density value of ca $30 \mu \mathrm{A} \mathrm{cm}^{-2}$. This behavior may be associated to the defects increase of the passive layer as a result of the increased aging time. The worst behavior was shown by sample aged for $100 \mathrm{~h}$, since the passivity domain (from OCP to breakdown potential) shrink and the anodic current density was permanently higher, reaching the current density value of around $0.8 \mathrm{~mA} \mathrm{~cm}^{-2}$ at low potential (130 mV vs. $\mathrm{Ag} / \mathrm{AgCl})$, which was related to pitting corrosion. 


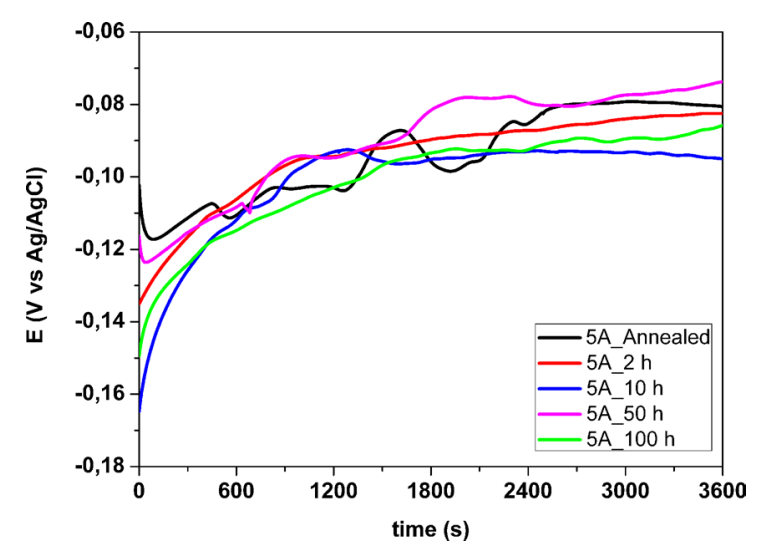

Figure 3. Typical evolution of open circuit potential with time of SDSS 5A.

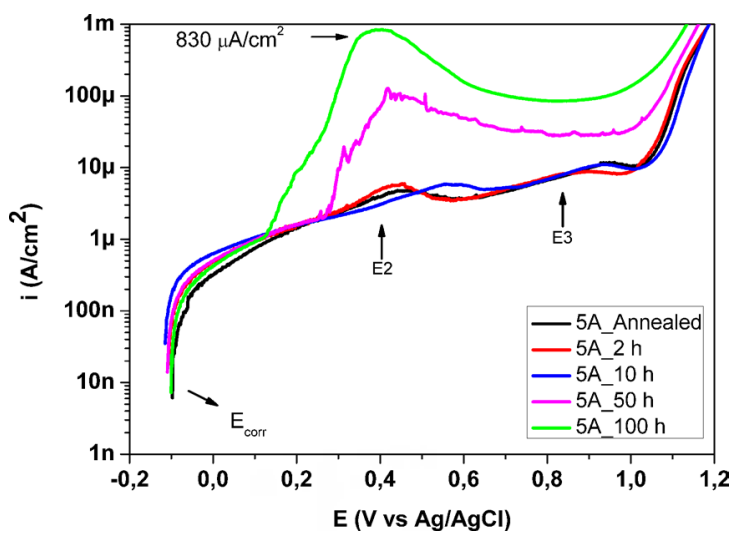

Figure 4. Anodic polarization curve in $60,000 \mathrm{ppm} \mathrm{NaCl}$. $\mathrm{E}_{\text {corr }}=$ corrosion potential, $\mathrm{E} 2=400 \mathrm{mV}, \mathrm{E} 3=850 \mathrm{mV}$ (vs. $\mathrm{Ag} / \mathrm{AgCl}$ ).

It is clear from Figure 4 that a longer heat treatment exhibits a strong effect on the passivation ability of the material. When the potential reaches the passivation state, a peak is detected at about $400 \mathrm{mV}$ vs. $\mathrm{Ag} / \mathrm{AgCl}$. This can be attributed to the microstructural changes that occur in ferrite phase due to thermal aging. As stated earlier, thermal aging at $475^{\circ} \mathrm{C}$ leads to fluctuation of the $\mathrm{Cr}$ concentration due to the formation of a $\mathrm{Cr}$-depleted region around $\alpha^{\prime}$ precipitate and therefore the $\mathrm{Cr}$ concentration varies from maximum to minimum values. $\mathrm{Cr}$, as a primary constituent of stainless steels, is known to be the most important element which influences the corrosion properties of stainless steels ${ }^{24,25}$. The variation in $\mathrm{Cr}$ concentration also leads to change in the current density/potential values and shape of polarization curves. During the anodic polarization experiment, the electrode surface of spinodally decomposed ferrite phase should undergo the same variation of $\mathrm{Cr}$ concentration, as the anodic dissolution of surface atoms gradually increases. Thereby, the variation of the $\mathrm{Cr}$ concentration markedly affects the passive film stability. A comparison of the curves clearly reveals an increase in the peak current density value as a function of aging time or the degree of embrittlement at $475^{\circ} \mathrm{C}$; the highest peak value was observed for the sample aged for $100 \mathrm{~h}\left(830 \mu \mathrm{A} \mathrm{cm}^{-2}\right)$, and the lowest peak value was of the sample aged for $2 \mathrm{~h}$. The surface analysis after the anodic polarization test reveals the presence of pits. The pit morphologies formed on the surface specimens were observed by optical microscopy and are shown in Figure 5. It was possible to observe an increase in the frequency of pits formed when the aging time increased up to $50 \mathrm{~h}$, and for times longer than $50 \mathrm{~h}$ an increase in the size of the pits formed was observed. For alloy aged for $100 \mathrm{~h}$, pits formed were more extensive and deeper. This morphological change is governed by the degree of passivity of oxide films formed on the specimen as function of aging time. These results are in good correlation with the anodic polarization curves, which showed that an increase in the aging time reduces the passive film stability, providing the conditions for the pit formation.

Three potentials were chosen from the polarization curves in order to evaluate the sample/film/solution behavior and their changes over the passivation range. Therefore, impedance measurements were performed in the potentials marked in the polarization curves of Figure 4 : corrosion potential $\left(\mathrm{E}_{\text {corr }}\right)$, $\mathrm{E} 2=400 \mathrm{mV}$ (vs. $\mathrm{Ag} / \mathrm{AgCl}$ ) potential (where the current peak was observed), $\mathrm{E} 3=850 \mathrm{mV}$ (vs. $\mathrm{Ag} / \mathrm{AgCl}$ ), close to the final passivation and/or onset of electrolyte oxidation. A qualitative evaluation of impedance was taken into account in the effect of potential on the diagrams.

Figure 6a shows the results of the EIS experiments carried out at corrosion potential. The Nyquist plots have almost the same shape, where depressed capacitive semicircles cover almost all the frequency regions. The similar behavior is in good agreement with the data obtained from the polarization curves (see Figure 4). From the Nyquist plots, it was possible to make an approximate estimate of the polarization resistance $\left(\mathrm{R}_{\mathrm{p}}\right)$ for each test by extrapolating the capacitive loop to the real axis. The polarization resistance, $R_{p}$, is commonly used as a measure of the resistance of a metal to corrosion damage. A high value of $\mathrm{R}_{\mathrm{p}}$ is associated with a high corrosion prevention capability; a low value of $\mathrm{R}_{\mathrm{p}}$ indicates potential high corrosion activity. Their values are plotted in Figure 7. As expected, the EIS polarization resistances at the corrosion potential of stainless steel $5 \mathrm{~A}$ do not alter significantly with the increase of heat treatment time. Therefore, these results suggested that, the protective role of the passive film formed on alloys were not degraded under open circuit corrosion conditions. However, the increasing potential is particularly deleterious in the case of the samples aged for 50 and 100 hours.

Figure 6(b) gives the results for the samples polarized at $400 \mathrm{mV}$ (vs Ag/ $\mathrm{AgCl}$ ). It is possible to note one capacitive loop at high frequency followed by a quite linear behavior in the lower frequency range. Interestingly, even with high current density, as observed for 50 hours, there is not an inductive loop that is ascribed to a dissolution process. Owing to the high current of the peak, the impedance for $100 \mathrm{~h}$ could 

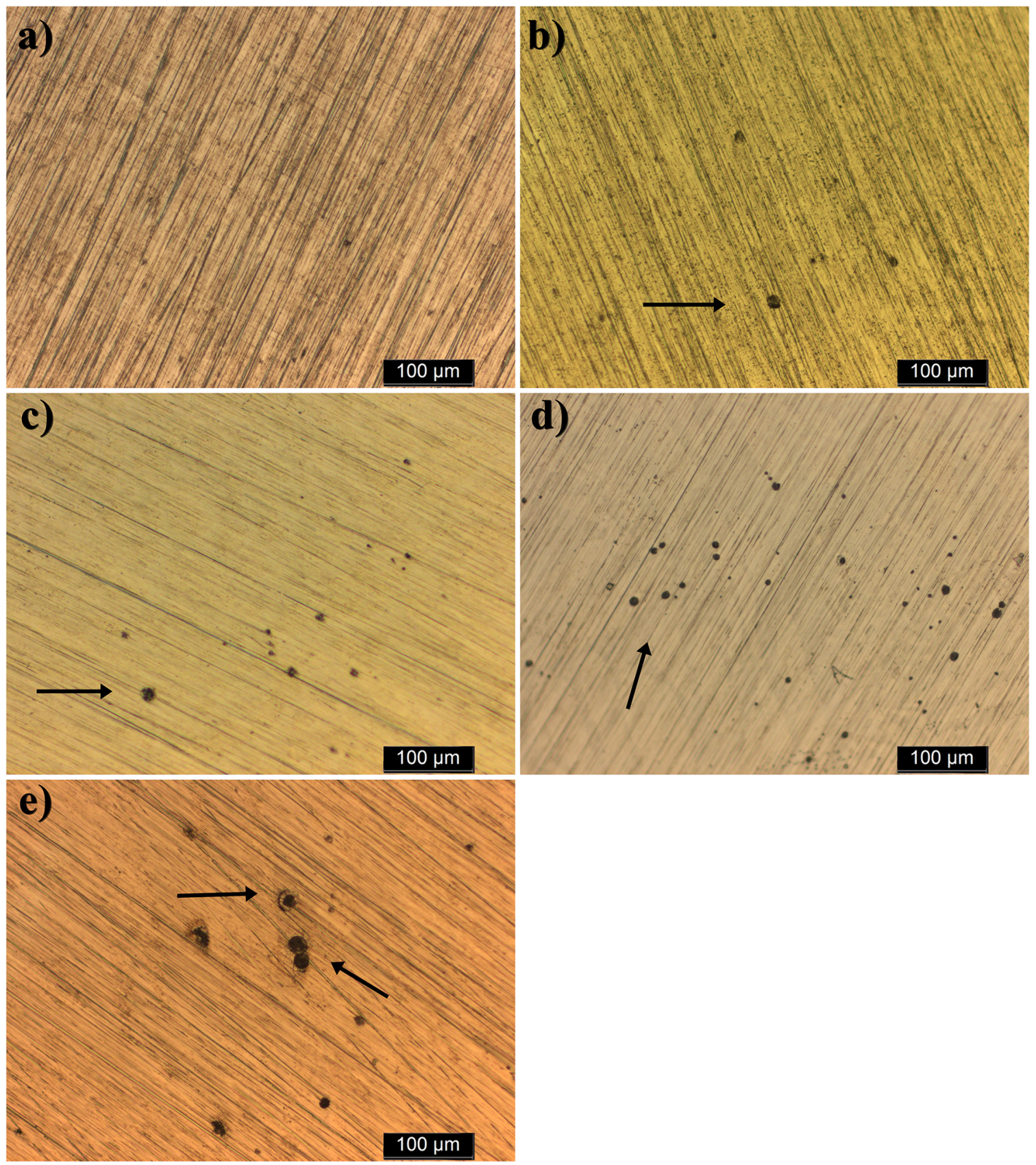

Figure 5. Optical micrographs showing pit morphologies formed on the surface after anodic polarization tests in a $60,000 \mathrm{ppm} \mathrm{NaCl}$

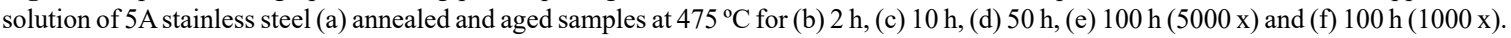

not be obtained experimentally. The sample heat-treated for $50 \mathrm{~h}$ presents a small impedance value, as expected for the more reactive surface. This significant decline in the impedance value illustrate the deteriorative effect of aging time on passivity condition at $400 \mathrm{mV}$ vs. $\mathrm{Ag} / \mathrm{AgCl}$ as it was previously shown in anodic potentiodynamic polarization results. This phenomenon can be described by passivity breakdown and localized corrosion. The impacts of aging treatment time and polarization at $400 \mathrm{mV}$ vs. $\mathrm{Ag} / \mathrm{AgCl}$ are better visualized by chronoamperometry tests in Figure 8 .
When the potential becomes very anodic (Figure 6(c)), $\mathrm{E} 3=850 \mathrm{mV}$ (vs. $\mathrm{Ag} / \mathrm{AgCl}$ ), one capacitive loop is detected in the high frequency range, followed by an inductive loop for the annealed and the aged for 2 and $10 \mathrm{~h}$ conditions. A small anodic peak can be noted in these conditions in the polarization curves. Probably the inductive loop is related to this increase of dissolution. For the sample aged for $50 \mathrm{~h}$, the behavior at low frequency is not related to an inductive loop, although the steady-state current density is high in this potential range. These electrochemical activities produce 

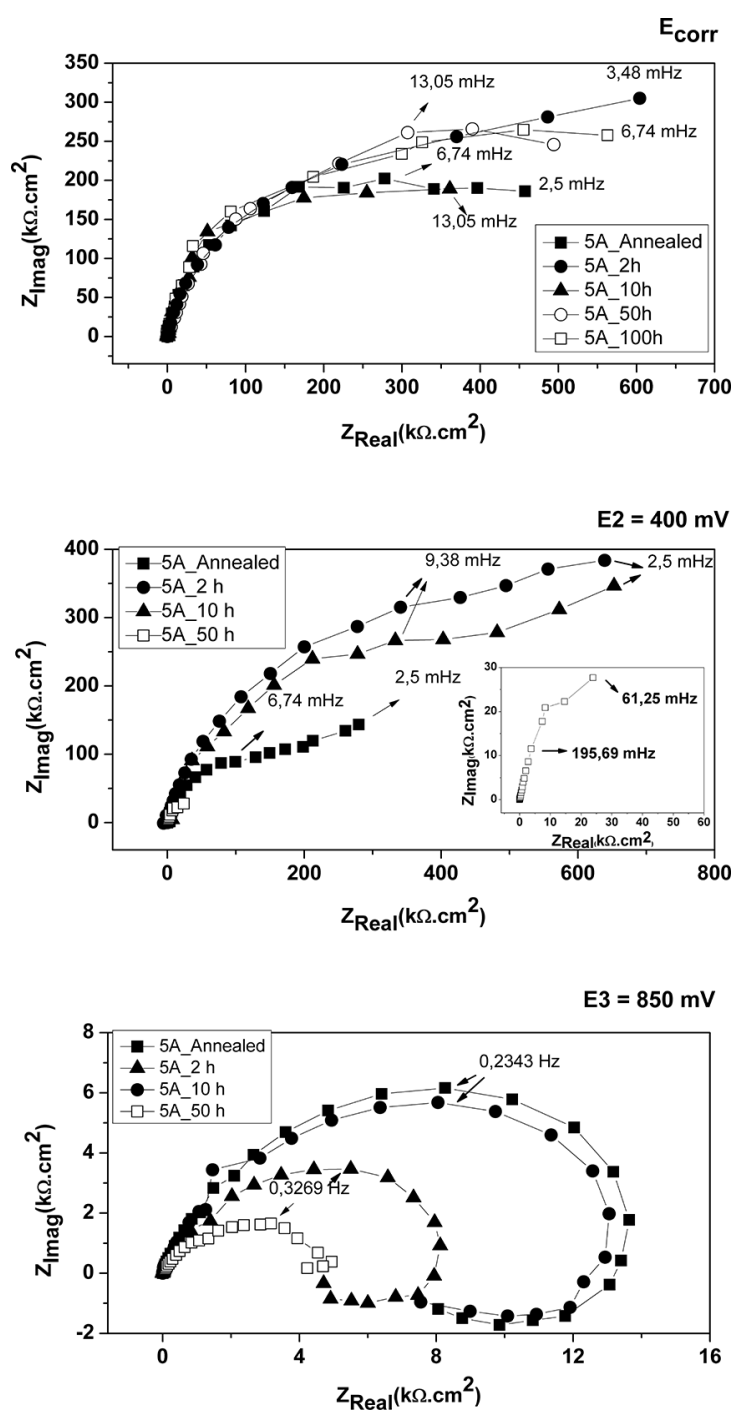

Figure 6. Nyquist plots of the super duplex stainless steel specimens at (a) corrosion potential, (b) $400 \mathrm{mV}$ and (c) $850 \mathrm{mV}$ vs. $\mathrm{Ag} / \mathrm{AgCl}$.

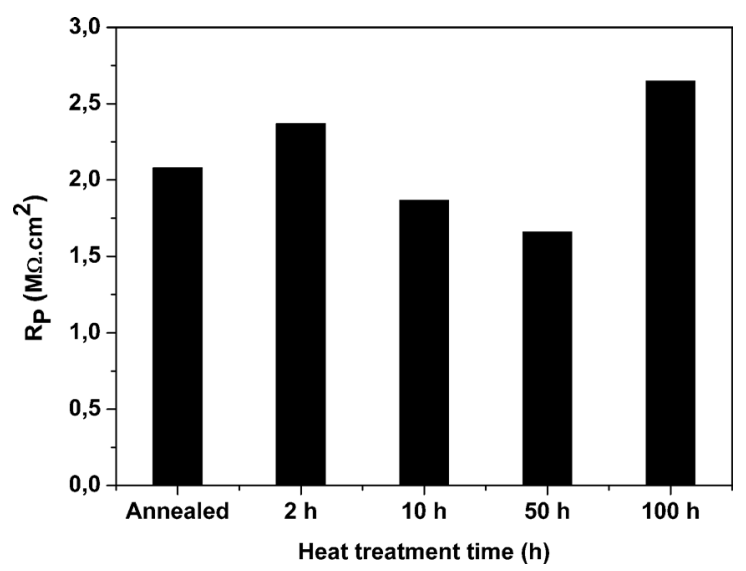

Figure 7. Variation of polarization resistance $\left(\mathrm{R}_{\mathrm{p}}\right)$ in $60,000 \mathrm{ppm} \mathrm{NaCl}$ test solution, estimated from Nyquist plots, with heat treatment time.

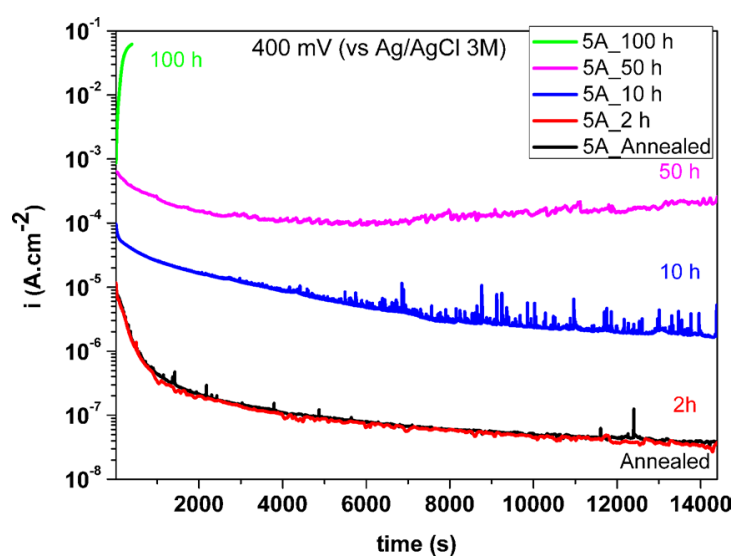

Figure 8. Current density -time curve at $400 \mathrm{mV}$ vs. $\mathrm{Ag} / \mathrm{AgCl}$ of samples annealed and aged at different times in $60,000 \mathrm{ppm} \mathrm{NaCl}$.

at $850 \mathrm{mV}$ a considerably lower impedance value when compared to impedance value measured at lower potentials.

In order to analyze the potential dependence of the steady-state passive currents, potentiostatic current-time measurements were carried out at potential of $400 \mathrm{mV}$ (vs. $\mathrm{Ag} / \mathrm{AgCl}$ ) for $4 \mathrm{~h}$. Figure 8 exhibits the current transient curves for all heat treatment conditions. For samples annealed and aged for 2 and 10 hours, the common feature of these plots is that a large current density is initially observed and then the current density remains nearly constant after a few hours (about $10 \mathrm{ks}$ ) of potential application indicating the attainment of a stable passive current density. However, current oscillations of short duration were detected. These spikes are especially present for the sample aged for $10 \mathrm{~h}$ and are considered to be related to film breakdown and the repassivation process associated with metastable pitting. For sample aged for $50 \mathrm{~h}$, a increase in the current density value was observed. The increase in the current density with aging time can be attributed to the microstructural evolution taking place during thermal aging. The results reveal that there is a significant decrease in passivation ability of the alloys by increase aging time.

From these current transients, it can be seen that in the chloride-containing solution, the current density drops following a classical high-field passivation theory ${ }^{26,27}$. The initial drastic current drop can be caused by the formation of a compact oxide film in the initial stage, which increases the resistance and reduces the current densities ${ }^{28}$. As the surface oxide layer grows or even becomes more compact, the kinetics of mass transport through the layer becomes slower, thus resulting in a decrease in the passivation current density. The steady-state behavior shows that the dissolution of the barrier layer takes place. Moreover, the barrier layer formation must contain a dissolution component. Nevertheless, this behavior is not observed for the sample aged at $475^{\circ} \mathrm{C}$ for $100 \mathrm{~h}$. For this 
condition, there is an increase in the current density throughout the test. It was necessary to stop the measurement because the current density increased quickly, reaching values around 0.1 A. No tendency to current stabilization was observed, then an intense dissolution occurred due presumably to the preferential corrosion attack of the $\mathrm{Cr}$-depleted regions as a result of the formation of Cr-rich $\alpha^{\prime}$ phase in the sample during aging. Since increasing the thermal aging time causes more segregation of $\mathrm{Cr}$ in the ferrite phase, this effect was more pronounced for the sample aged at $475^{\circ} \mathrm{C}$ for $100 \mathrm{~h}$.

These results suggested that, for the aging carried out for less than 10 hours, a similar behavior to the solution annealing sample is observed. For longer aging times, the tendency towards dissolution increasing with exposure time in the medium is noted.

Figure 9(a) shows the surface morphology of the alloy aged for $100 \mathrm{~h}$ at $475^{\circ} \mathrm{C}$, after the chronoamperometry tests in $60,000 \mathrm{ppm} \mathrm{NaCl}$ at $25^{\circ} \mathrm{C}$. The dark area indicates the region corroded locally, and in addition, several pits were found in this area. Thus, the significant increase of current observed in the anodic polarization curves around $400 \mathrm{mV}$ (vs. $\mathrm{Ag} / \mathrm{AgCl}$ ) may be associated with the film breakdown processes with pitting formation. According to the EDS composition analysis, the dark area showed very high $\mathrm{Cr}$ content as seen in Figure 9(b). The value found for the sample aged for 100 hours corresponded to almost twice the nominal Cr content of the alloy (Figure 9(c) and (d)). The results can be taken as an indication that these are Cr-rich $\alpha^{\prime}$ phase, a fact that is in good agreement with the findings of earlier studies ${ }^{7,8,9}$. Park and Kwon (2005), for a 24.6Cr-6.6Ni-3.12Mo-0.25N duplex stainless steel aged at $475^{\circ} \mathrm{C}$ for $300 \mathrm{~h}$, reported EDS analysis for the pits found in ferrite phase, after electrochemical noise measurement, and showed also a very high $\mathrm{Cr}$ content. In the previous study $^{7}$, they suggested that numerous micro-galvanic cells of a few nanometer scale formed between $\mathrm{Cr}$-rich $\alpha^{\prime}$ phase and neighboring Fe-rich $\alpha$ phase in the ferrite matrix of the aged samples. These nanometer scale galvanic couples, distributed throughout the entire ferrite matrix, appear to lead to uniform dissolution of ferrite phase by galvanic corrosion.

The corrosion properties of both ferrite and austenite are dependent on the actual chemical composition. The main alloying elements, i.e., chromium, molybdenum, nickel, and nitrogen, are not equally distributed in ferrite and austenite.

a)
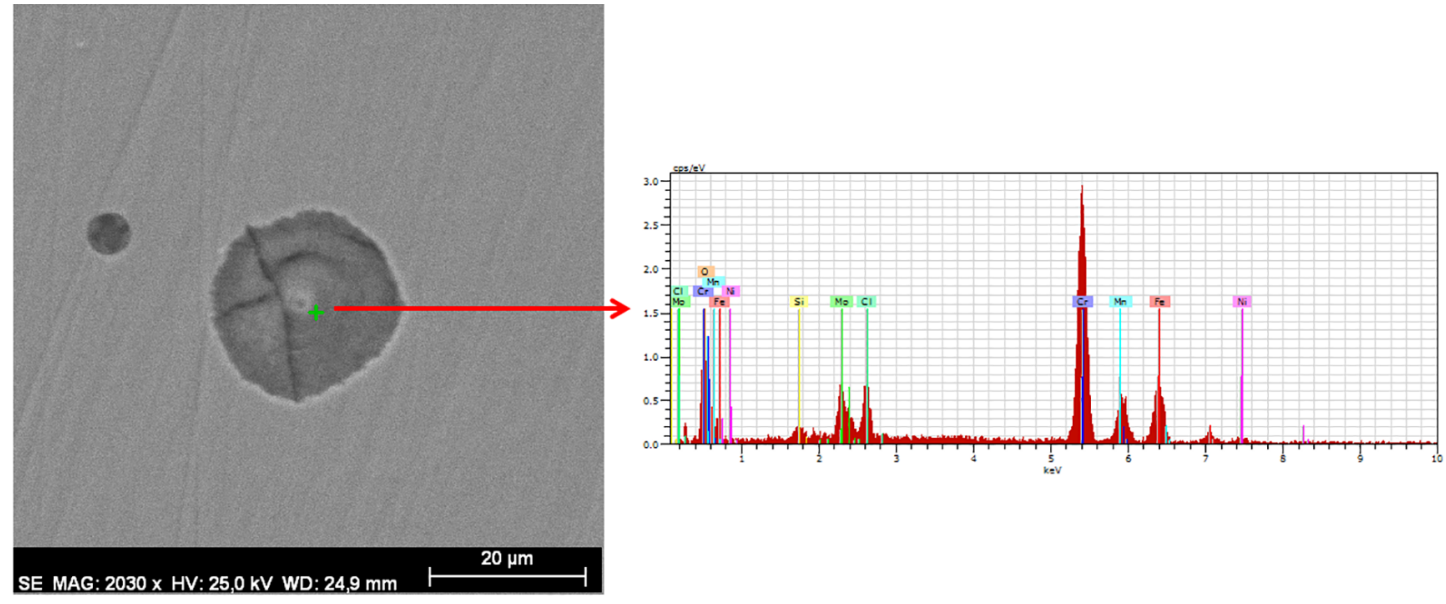

b)
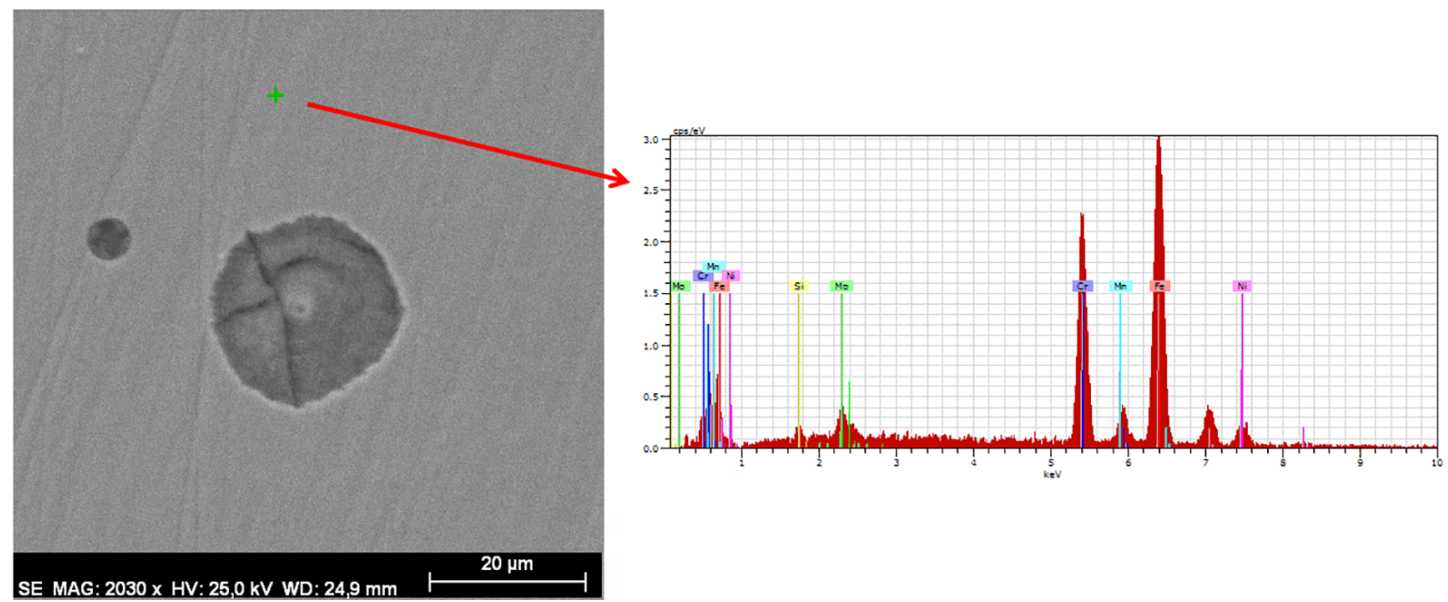

Figure 9. (a) Surface morphology of the alloy aged for $100 \mathrm{~h}$ at $475^{\circ} \mathrm{C}$, after chronoamperometry tests (b) EDS spectrum showing the surface composition of the dissolved area shown in (a); (c) SEM image and (d) energy dispersive spectrometer of SDSS aged for $100 \mathrm{~h}$ at $475^{\circ} \mathrm{C}$. 
Austenite is enriched with nickel and nitrogen, while ferrite is enriched with chromium and molybdenum. The heat treatment temperature and time strongly affect the amount, composition and morphology of the ferrite and austenite phases of duplex stainless steels ${ }^{24,29}$. The difference in chemical composition between the ferritic and the austenitic phases can greatly affect the corrosion behavior of duplex stainless steel (DSS). It has been found that selective dissolution of the respective constituent phases can occur in various DSSs in different solutions s,30,31. $^{\text {. }}$

A galvanic cell is formed when two dissimilar metals are connected electrically while both are immersed in a solution. In order to evaluate the microstructural differences caused by aging at $475^{\circ} \mathrm{C}$, galvanic experiments were performed for $24 \mathrm{~h}$, by coupling the annealed sample and aged samples in $60,000 \mathrm{ppm} \mathrm{NaCl}$ at $25^{\circ} \mathrm{C}$. The galvanic corrosion measurements occur close to the corrosion potential, and there is no polarization. Therefore, the observed difference arises due to the nature of the formed film. The galvanic current density and the common potential were recorded, yielding graphs such as those presented in Figure 10. As the electrode was connected, the galvanic current density was negative when the annealed sample was in a cathodic situation and consequently the aged sample was in an anodic
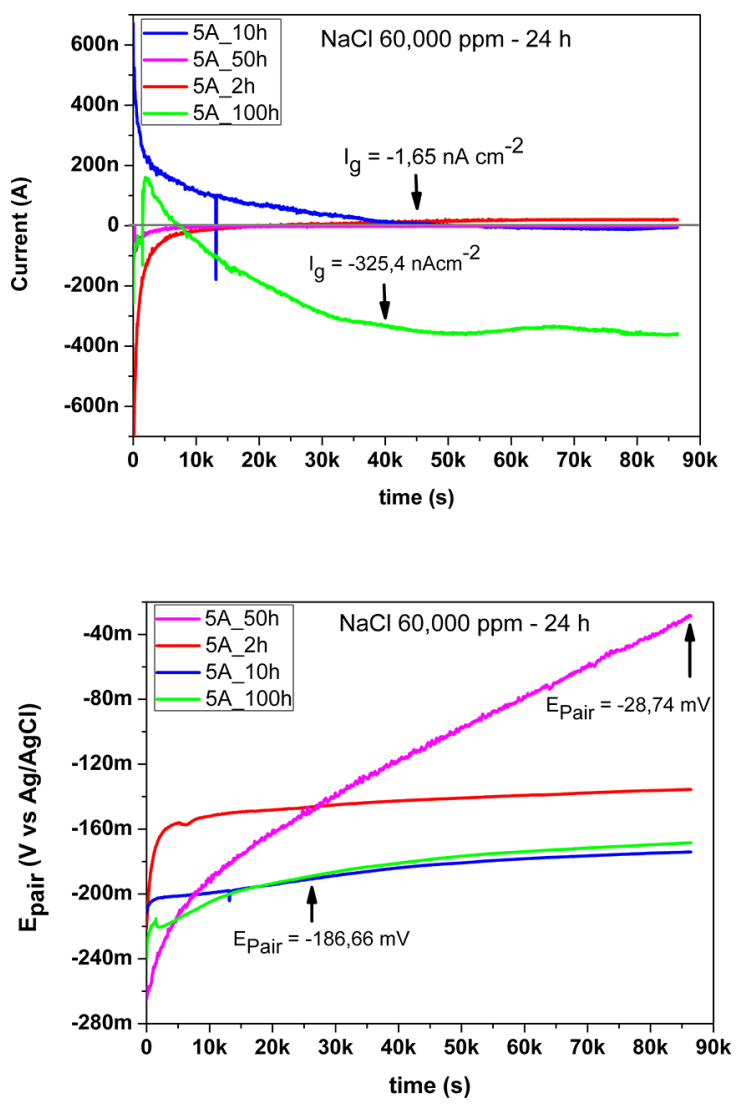

Figure 10. Galvanic corrosion between annealed and aged samples in $60,000 \mathrm{ppm} \mathrm{NaCl}$ for 24 hours. situation. Conversely, positive current corresponds to the inverse case. The annealed sample was always set as the reference specimen.

The galvanic current density was negative just for the coupled annealed and aged for $100 \mathrm{~h}$ at $475^{\circ} \mathrm{C}$ samples. This result shows that it was essentially the sample aged for 100 $\mathrm{h}$ that was undergoing corrosion by galvanic coupling. In the case of other samples coupled with annealed samples, the galvanic current density detected by the potentiostat reached very small values (about $-1.0 \mathrm{nA} \mathrm{cm}^{-2}$ ) that were practically negligible. After $24 \mathrm{~h}$ the current was almost null, showing that they have a similar electrochemical behavior that inhibited the occurrence of galvanic corrosion. Thus, aging up to $50 \mathrm{~h}$ did not weaken the microstructure of these samples. Furthermore, when the annealed sample was linked to the sample aged for $100 \mathrm{~h}$, for the same time exposure of $24 \mathrm{~h}$, a higher negative galvanic current density was observed (about $-325 \mathrm{nA} \mathrm{cm}^{-2}$ ), and this current remained relatively high for the rest of the test. This suggests that galvanic corrosion behavior of the alloy aged for $100 \mathrm{~h}$ is different from that of the solution annealed alloy. These large change is associated with microstructural differences between the two samples and has been attributed to the fluctuations in the chemical composition of ferrite grains as a result of the variation in the degree of Cr depletion for the thermally aged sample ${ }^{7,8,9}$. These results are in good agreement with those obtained by Chronoamperometric studies of the sample aged at 475 ${ }^{\circ} \mathrm{C}$ for $100 \mathrm{~h}$, where an intense dissolution was observed due presumably to the preferential corrosion attack in $\mathrm{Cr}$ depleted regions as a result of the precipitation of $\mathrm{Cr}$-rich $\alpha^{\prime}$ precipitates in the sample during aging.

\section{Conclusions}

1. The ferrite microhardness undergoes a marked increase of approximately $40 \%$ in the initial hours of aging, and reaches the highest value for the sample aged at $475^{\circ} \mathrm{C}$ for $100 \mathrm{~h}$. The accentuated increase in ferrite hardening was related to the obstruction of the movement of dislocations caused by the precipitation of nanometric scale $\alpha^{\prime}$ phase. In contrast, the hardness of austenite phase remains essentially unchanged, indicating that the austenite is unaffected by the aging treatment.

2. The degradation in the film stability of the SDSS aged at $475^{\circ} \mathrm{C}$, confirmed by an anodic peak detected at about $400 \mathrm{mV}$ vs. $\mathrm{Ag} / \mathrm{AgCl}$ in the passive range during anodic polarization, results from the microstructural changes that occur in ferrite phase due to thermal aging. Since thermal aging at 475 ${ }^{\circ} \mathrm{C}$ leads to fluctuation of the $\mathrm{Cr}$ concentration due to the formation of a $\mathrm{Cr}$-depleted region around $\alpha$ ' precipitate, the $\mathrm{Cr}$ concentration varies from maximum to minimum values. 
3. Chronoamperometric studies have revealed no tendency to current stabilization for the sample aged at $475^{\circ} \mathrm{C}$ for $100 \mathrm{~h}$, then an intense dissolution occurs due presumably to the preferential corrosion attack of the $\mathrm{Cr}$-depleted regions as a result of the precipitation of Cr-rich $\alpha^{\prime}$ precipitates in the sample during aging. Thereby, increasing the thermal aging time causes more segregation of $\mathrm{Cr}$ in the ferrite phase and this effect was more pronounced for the sample aged at $475^{\circ} \mathrm{C}$ for $100 \mathrm{~h}$.

\section{Acknowledgments}

The authors wish to acknowledge the financial support by Coordenação de Aperfeiçoamento de Pessoal de Nivel Superior (Capes) and Petrobras.

\section{References}

1. Lv J, Liang T, Dong, Wang C. Influence of sensitization on microstructure and passive property of AISI 2205 duplex stainless steel. Corrosion Science. 2016;104:144-151.

2. Bastos IN, Tavares SSM, Dalard F, Nogueira RP. Effect of microstructure on corrosion behavior of super duplex stainless steel at critical environment conditions. Scripta Materialia. 2007;57(10):913-916.

3. Costa EV, Mesquita TJ, Ferreira A, Nogueira RP, Bastos IN. Effect of carbon dioxide and temperature on passive film parameters of superduplex stainless steel. Materials Research. 2013;16(4):929-936.

4. Tavares SSM, Pardal JM, Lima LD, Bastos IN, Nascimento AM, de Souza JA. Characterization of microstructure, chemical composition, corrosion resistance and toughness of a multipass weld joint of superduplex stainless steel UNS S32750. Materials Characterization. 2007;58(7):610-616.

5. Smiderle J, Pardal JM, Tavares SSM, Vidal ACN. Premature failure of superduplex stainless steel pipe by pitting in sea water environment. Engineering Failure Analysis. 2014;46:134-139.

6. Sahu JK, Krupp U, Ghosh RN, Christ HJ. Effect of $475{ }^{\circ} \mathrm{C}$ embrittlement on the mechanical properties of duplex stainless steel. Materials Science and Engineering: A. 2009;508(1-2):114.

7. Park CJ, Know HS. Effects of aging at $475^{\circ} \mathrm{C}$ on corrosion properties of tungsten-containing duplex stainless steels. Corrosion Science. 2002;44(12):2817-2830.

8. Iacoviello F, Casari F, Gialanella S. Effect of $" 475{ }^{\circ} \mathrm{C}$ embrittlement" on duplex stainless steels localized corrosion resistance. Corrosion Science. 2005;47(4):909-922.

9. Park CJ, Know HS. Electrochemical noise analysis of localized corrosion of duplex stainless steel aged at $475^{\circ} \mathrm{C}$. Materials Chemistry and Physics. 2005;91(2-3):355-360.

10. Mateo A, Llanes L, Anglada M, Redjaimia A, Metauer G. Characterization of the intermetallic G-phase in an AISI 329 duplex stainless steel. Journal of Materials Science. 1997;32(17):4533-4540.
11. Danoix F, Auger P. Atom Probe Studies of the Fe-Cr System and Stainless Steels Aged at Intermediate Temperature: A Review. Materials Characterization. 2000;44(1-2):177-201.

12. Li S, Wang Y, Wang X, Xue F. G-phase precipitation in duplex stainless steels after long-term thermal aging: A high-resolution transmission electron microscopy study. Journal of Nuclear Materials. 2014;452(1-3):382-388.

13. Danoix F, Auger P, Blavette D. Hardening of aged duplex stainless steels by spinodal decomposition. Microscopy and Microanalysis. 2004;10(3):349-354.

14. Qiu JH. Passivity and its breakdown on stainless steels and alloys. Surface and Interface Analysis. 2002;33(1011):830-833.

15. Zheng ZB, Zheng YG, Sun WH, Wang JQ. Effect of applied potential on passivation and erosion-corrosion of a Fe-based amorphous metallic coating under slurry impingement. Corrosion Science. 2014;82:115-124.

16. Fernández-Domene RM, Blasco-Tamarit E, García-García DM, García-Antón J. Passive and transpassive behaviour of Alloy 31 in a heavy brine LiBr solution. Electrochimica Acta. 2013;95:1-11.

17. Chandra K, Singhal R, Kain V, Raja VS. Low temperature embrittlement of duplex stainless steel: Correlation between mechanical and electrochemical behavior. Materials Science and Engineering: A. 2010;527(16-17):3904-3912.

18. Jiang XC, Yoshimura T, Ishikawa Y, Shinohara T, Tsujikawa S. Investigation of Alpha Prime Precipitation in Aged Duplex Stainless Steel. Journal of the Electrochemical Society. 1992;139(4):1001-1007.

19. Martins M, Casteletti LC. Heat treatment temperature influence on ASTM A890 GR 6A super duplex stainless steel microstructure. Materials Characterization. 2005;55(3):225233.

20. Tucker JD, Miller MK, Young GA. Assessment of thermal embrittlement in duplex stainless steels 2003 and 2205 for nuclear power applications. Acta Materialia. 2015;87:1524.

21. Pareige C, Emo J, Saillet S, Domain C, Pareige P. Kinetics of G-phase precipitation and spinodal decomposition in very long aged ferrite of a Mo-free duplex stainless steel. Journal of Nuclear Materials. 2015;465:383-389.

22. Della Rovere CA, Santos FS, Silva R, Souza CAC, Kuri SE. Influence of long-term low-temperature aging on the microhardness and corrosion properties of duplex stainless steel. Corrosion Science. 2013;68:84-90.

23. Alonso-Falleiros N, Hakim A, Wolynec S. Comparison Between Potentiodynamic and Potentiostatic Tests for Pitting Potential Measurement of Duplex Stainless Steels. Corrosion Science. 1999;55(5):443-448.

24. Sedriks AJ. Corrosion of Stainless Steels. $2^{\text {nd }}$ ed. New York: John Wiley and Sons; 1996. p. 47-74.

25. Cíhal V. Intergranular Corrosion of Steels and Alloys. New York: Elsevier Science; 1984. p. 4-43. 
26. Munirathinam B, Narayanan R, Neelakantan L. Electrochemical and semiconducting properties of thin passive film formed on titanium in chloride medium at various $\mathrm{pH}$ conditions. Thin Solid Films. 2016;598:260-270.

27. Linarez Pérez OE, Fuertes VC, Pérez MA, López Teijelo M. Characterization of the anodic growth and dissolution of oxide films on valve metals. Electrochemistry Communications. 2008;10(3):433-437.

28. Ibrahim MA, Pongkao D, Yoshimura M. The electrochemical behavior and characterization of the anodic oxide film formed on titanium in $\mathrm{NaOH}$ solutions. Journal of Solid State Electrochemistry. 2002;6(5):341-350.
29. Souza EC, Rossitti S, Rollo JMDA. Influence of chloride ion concentration and temperature on the electrochemical properties of passive films formed on a superduplex stainless steel. Materials Characterization. 2010;61(2):240-244.

30. Femenia M, Pan J, Leygraf C. In Situ Local Dissolution of Duplex Stainless Steels in $1 \mathrm{M} \mathrm{H}_{2} \mathrm{SO}_{4}+1 \mathrm{M} \mathrm{Nacl}$ by Electrochemical Scanning Tunneling Microscopy. Journal of the Electrochemical Society. 2002;149(6):B187-B197.

31. Femenia M, Pan J, Leygraf C, Luukkonen P. In situ study of selective dissolution of duplex stainless steel 2205 by electrochemical scanning tunnelling microscopy. Corrosion Science. 2001;43(10):1939-1951. 